\title{
Comparison of Sacral Ratio Between Children with Chronic Constipation and Control Group
}

\author{
Narges Afzali, ${ }^{1}$ Abdolreza Malek, ${ }^{2, *}$ and Ladan Cheraghzadeh ${ }^{1}$ \\ ${ }^{1}$ Department of Radiology, Mashhad Medical Sciences Branch, Islamic Azad University, Mashhad, Iran \\ ${ }^{2}$ Department of Pediatrics, Faculty of Medicine, Mashhad University of Medical Sciences, Mashhad, Iran \\ ${ }^{3}$ Mashhad Medical Sciences Branch, Islamic Azad University, Mashhad, Iran \\ "Corresponding author: Abdolreza Malek, Department of Pediatrics, Imam-Reza Hospital, Mashhad, Iran. Tel: +98-9153131417, E-mail: malekar@mums.ac.ir
}

Received 2016 August 23; Revised 2017 February 18; Accepted 2017 March 19.

\begin{abstract}
Background: Chronic constipation is a common problem in children and makes a significant portion of the outpatient visits. Because sacral disorders would impair the defecating mechanism, this study was aimed to evaluate sacral ratio (SR) as a criterion of sacral bone and its association with chronic constipation.

Methods: This study was performed on 52 children aged 0 - 15 years referred to the radiology department during 2014 - 2015. The case group included 26 patients with chronic functional constipation and the control group included 26 others without chronic constipation, which had been referred for pelvic radiography for other reasons such as trauma or suspected hip joint problem; Anterior-posterior pelvic radiography was done for both case and control groups and SR in each group was calculated and compared. Results: The case group included 14 females and 12 males with average age of $5.20 \pm 3.61$ years and the control group included 20 females, and 6 males with average age of $6.97 \pm 4.09$ years. The defecation occurred once a week in $50 \%$ of all children in study group, $26 \%$ of them had no defecation in a week. In control group, $54 \%$ had defecation once or twice a day. Mean SR in the study group was $0.8 \pm 0.12$ and the control group was $0.826 \pm 0.15$, but the difference was not statistically significant $(\mathrm{P}>0.05)$. Other variables including gender and times of defecation did not show significant relation with SR. The mean of SR in continent cases was more than incontinent cases, although not statistically significant $(P=0.216)$.

Conclusions: In this study, SR showed a wide range of values in both groups and the mean SR in control group was more than the study group but this difference was not statistically significant. Therefore, the sacral ratio canot be seen as a useful tool for evaluating chronic constipation in children.
\end{abstract}

Keywords: Constipation, Sacral ratio, Defecation

\section{Background}

Constipation in children is a long-lasting functional disorder with a worldwide prevalence. Up to one third of children between 6 and 12 years report constipation during any given year (1-5). Children with constipation have higher prevalence rates for fecal and urinary incontinence than those without it (6). A thorough medical history and physical examination, including a rectal examination in combination with a bowel diary, is sufficient in the majority of cases for diagnosis of constipation $(7,8)$. Although organic causes of constipation are uncommon and often become apparent in the first month of life, they must be considered in all cases. For 90\% - 95\% of children with constipation the problem is functional. A family history of constipation may be present $(9,10)$. Case-control studies have shown an association between low dietary fiber and lower energy and nutrient intake in cases with constipation compared with controls $(11,12)$.

Growth and development is normal in most children with constipation $(13,14)$. Behavioral disorders and psy- chosocial factors in children with constipation, with or without incontinence, are also important and it remains unclear whether these are predisposing or just maintaining factors for constipation. Chronic constipation can cause fecal retention, rectal distension, and disturbed sensory and motor function (15).

Constipation occurs in wide range of pediatric age from infancy to adolescence. It occurs more common during three stages of childhood: during weaning, in toilet training, and in school-aged children. Different studies reported that about half of childhood constipation occurs in the first year of life $(16,17)$. Before puberty, constipation is equally seen between girls and boys but after that, females are more prone to develop constipation $(18,19)$.

Constipation can be difficult to treat and often requires prolonged support, explanation, and medical treatment. The possibility of developmental abnormalities such as anorectal malformations and sacral anomalies should be considered at this stage. Sacral bone disorders including partial or complete sacral agenesis can lead to fecal and uri- 
nary disorders such as urinary reflux, repetitive urinary infections, incontinence and constipation.

Regarding importance of this issue, we aimed to evaluate the sacral ratio between normal children and children suffering from chronic constipation to determine whether sacral dysplasia is more common in children with chronic constipation.

\section{Methods}

This was a case-control study on 52 children. Study group included 26 cases suffering from chronic constipation and the control group consisted of 26 children with normal bowel habits. Pelvic radiography was done in control group for different causes such as assessment of urolithiasis, backache, trauma, suspicious arthritis and hip joint problems. Abdominopelvic radiography and barium enema was performed in children with constipation in order to exclude Hirschsprung's disease. Children, in whom functional constipation was confirmed after ruling out organic disorders, entered the study as case group. The study was performed from May 2014 to May 2015 at the radiology department of Islamic Azad University of Mashhad. Chronic constipation was defined as decreased defecation twice or less per week or bullet or stiff stool for at least two weeks. Children with any structural anomaly in fecal and urinary systems such as imperforate anus, cloacal anomalies, Hirschsprung's disease, and anorectal atresia, children with neurologic problems like spina bifida, myelomeningocele, meningocele or history of surgery on spinal cord or spine because of clubfoot or scoliosis were excluded from the study.

Sample size was obtained 36 per each group according to Kajbafzadeh (20), with $99 \%$ of confidence coefficient, and $90 \%$ of test power. The collecting data was conducted via checklist and variables age, gender, sacral ratio (SR), fecal continence and chronic constipation. were evaluated.

Sacral ratio was measured using anteroposterior pelvic radiography. At first a horizontal line was drawn crossing the highest point of sacroiliac (SI) joints of the two sides (X), Another line crossed the lowest point of SI joints (Y). Finally, the last line crossed the lowest point of sacrum $(\mathrm{Z})$. To calculate the sacral ratio (SR), the digits were put into following equation:

$S R=\frac{Y Z}{X Y}$

After determining the SR, we compared the values between two groups in relation to age, gender and weight, height and bowel continence.

\subsection{Data Analysis}

To describe the data, tables and statistical indices mean, standard deviation, and median were used, and to make a better knowledge of numerical variables, histograms were used. Qualitative data were analyzed by Kolmogorov Smirnov; and t-test was used because of normal distribution of data. To control the other variables, we used multivariate variance. The data were analyzed by IBM SPSS V.20. Significance level was considered less than $5 \%$.

\subsection{Ethical Consideration}

Unnecessary radiography was not requested for children in case and control groups. No extra charge burden was imposed on the patients' parents. Ethical committee of medical school approved the study.

\section{Results}

Mean age of controls was higher than that of chronic constipation group; 6.97 years vs 5.2; no significant difference was observed between the two groups, $(P=0.103)$. Also the averages of weight, and height were higher in control group than in study group; however, this difference was not significant for either weight $(P=0.422)$, or height $(P=0.076)$.

In control group, mean sacral ratio (SR) was 0.826 , while it was 0.8 in study group. In evaluation of relation between both groups, t-test did not show a significant difference for $\mathrm{SR}(\mathrm{P}=0.574)$.

In study group, 14 (54\%) cases were female and 12 (46\%) were male, but in control group girls were 20 (77\%) and boys were 6 (23\%). There was no significant difference between groups considering the gender $(\mathrm{P}>0.05)$. Sacral ratio was also evaluated in girls and boys of both groups separately; but no significant difference was found $(\mathrm{P}=0.865$ for females, $\mathrm{P}=0.418$ for males) (Table 1 ).

As for toilet training, the children were divided into two groups: $\leq 4$ years and $>4$ years. SR did not show any significant difference between older and younger than four years in case and control groups ( $\mathrm{P}>0.05)$ (Table 1$)$.

Stool frequency in $50 \%$ of case group was once a week and $26 \%$ had no defecation in a week. In control group, 54\% of all cases had bowel movemens once or twice a week. In case group, 10 (38.5\%) of cases had bowel continence, while in control group most of them were bowel continent. In 23 (88.5\%) cases; distribution of fecal continence showed significant difference between case and control groups $(\mathrm{P}<$ 0.0001 ); but sacral ratio was not statistically different between the two groups (Table 1). 


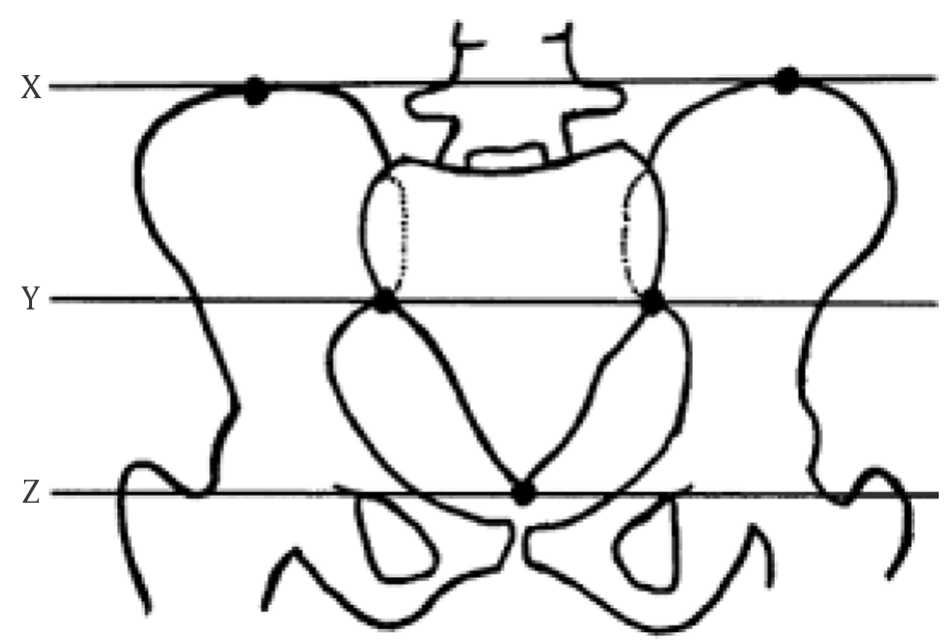

Figure 1. Anatomical View

Table 1. Sacral Index Relation According to Age, Sex and Fecal Continence in Children with Constipation Comparing with Control Group

\begin{tabular}{|c|c|c|c|c|c|}
\hline \multirow[t]{2}{*}{ SR Ratio } & \multicolumn{2}{|c|}{ Case Group, $n=26$} & \multicolumn{2}{|c|}{ Control Group, $\mathbf{n}=26$} & \multirow[t]{2}{*}{ P Value } \\
\hline & Mean & Standard Deviation & Mean & Standard Deviation & \\
\hline \multicolumn{6}{|l|}{ Age } \\
\hline$\leq 4$ years & 0.792 & 0.115 & 0.734 & 0.182 & 0.415 \\
\hline$>4$ years & 0.813 & 0.128 & 0.860 & 0.132 & 0.305 \\
\hline \multicolumn{6}{|l|}{ Gender } \\
\hline Female & 0.840 & 0.120 & 0.831 & 0.166 & 0.865 \\
\hline Male & 0.763 & 0.113 & 0.810 & 0.116 & 0.418 \\
\hline \multicolumn{6}{|l|}{ Bowel continence } \\
\hline Continent & 0.842 & 0.145 & 0.826 & 0.153 & 0.775 \\
\hline Incontinent & 0.781 & 0.101 & 0.830 & 0.199 & 0.513 \\
\hline
\end{tabular}

\section{Discussion}

The sacral ratio is a point of reference to detect the sacral dysplasia in patients with anorectal malformations (21). In present study, the sacral ratio of children with chronic constipation is compared with that of a healthy group to determine if it can be used as a predictor factor in pediatric constipation.

We evaluated the SR index in relation to age, gender, weight, height, and the frequency of defecation a week in case and control groups. According to these variables, SR did not show a statistically important difference between case and control groups.

Based on the age of toilet training, we analyzed the SR in children dividing them into younger and older than four years old. SR index increased by the age but no signifi- cant difference was found between these groups. Similarly, Oh et al. (2000) did not report any correlation between SR and patients' age (22).

Kajbafzadeh and colleagues (2008) have also shown that the SR is not correlated with age in pediatric population, but in children with urinary infection or constipation SR is low in the range of 1 - 3 year olds and it was significantly increased in those aged 12 - 15 years (20).

Kajbafzade (20) (2008) and Pena (23) (1995) reported that all children with normal defecation had SR higher than 0.3 , They concluded that the values below 0.4 were definitely related with abnormalities.

Similar to the present study, Caisedo et al. (24) (2015) found that the sacral index in patients with vesicoureteral reflux and constipation did not show significant variation compared to the normal pediatric population, but in 
anorectal malformations specially in high subtypes, the SR values was below the average.

Torre et al. (25) (2001) studied the sacral development in anorectal malformations and in normal population. They observed complete bowel continence in $48 \%$ of children with normal SR, while only $17 \%$ of cases with low SR showed bowel continence. Macedo et al. (26) examined the sacral ratio and fecal continence in children with anorectal malformations. Consistent with the results of present study, they reported that there was no significant difference for SR between children with complete/relative defecation control and those cases who were incontinent for defecation.

Ahmadi et al. (27) (2005) evaluated the sacral ratio as a prognostic factor in patients with anorectal malformations. They concluded that the abnormal SR $<0.7$ correlates with poor defecation function and declared that sacral segment and SR are important factors in postoperative fecal function in anorectal malformations.

It should be noted that because of number of subjects in this study there were important limitations. Research on larger groups would allow the validation of the sacral index as a predictor and prognostic factor in children with chronic constipation and fecal complaints.

\subsection{Conclusion}

In this study, SR showed a wide range of values in both case and control groups, the mean of SR in control group was more than the study group but this difference was not statistically significant. Therefore, the sacral ratio cannot be used as a reliable index to evaluate chronic constipation in children.

\section{References}

1. Mugie SM, Di Lorenzo C, Benninga MA. Constipation in childhood. Nat Rev Gastroenterol Hepatol. 2011;8(9):502-11. doi: 10.1038/nrgastro.2011.130. [PubMed: 21808283].

2. Mugie SM, Benninga MA, Di Lorenzo C. Epidemiology of constipation in children and adults: a systematic review. Best Pract Res Clin Gastroenterol. 2011;25(1):3-18. doi: 10.1016/j.bpg.2010.12.010. [PubMed: 21382575].

3. van Dijk M, Benninga MA, Grootenhuis MA, Last BF. Prevalence and associated clinical characteristics of behavior problems in constipated children. Pediatrics. 2010;125(2):e309-17. doi: 10.1542/peds.2008-3055. [PubMed: 20083527].

4. Rajindrajith S, Devanarayana NM. Constipation in children: novel insight into epidemiology, pathophysiology and management. J Neurogastroenterol Motil. 2011;17(1):35-47. doi: 10.5056/jnm.2011.17.1.35. [PubMed: 21369490].

5. van den Berg MM, Benninga MA, Di Lorenzo C. Epidemiology of childhood constipation: a systematic review. Am J Gastroenterol. 2006;101(10):2401-9. doi: 10.1111/j.1572-0241.2006.00771.x. [PubMed: 17032205].

6. Loening-Baucke V. Prevalence rates for constipation and faecal and urinary incontinence. Arch Dis Child. 2007;92(6):486-9. doi: 10.1136/adc.2006.098335. [PubMed: 16857698].
7. Ausma J, Ruth M, Levine A, Benninga M. Prucalopride in children with functional constipation: A randomized, multicenter, placebocontrolled trial. Unraveling childhood constipation. 2014;119.

8. Lembo A, Camilleri M. Chronic constipation. $N$ Engl J Med. 2003;349(14):1360-8. doi: 10.1056/NEJMra020995. [PubMed: 14523145].

9. Roma E, Adamidis D, Nikolara R, Constantopoulos A, Messaritakis J. Diet and chronic constipation in children: the role of fiber. J Pediatr Gastroenterol Nutr. 1999;28(2):169-74. [PubMed: 9932850].

10. Steffen R. Diet and chronic constipation in children: The role of fiber. Clin Pediatr. 2000;39(4):250.

11. Morais MB, Vitolo MR, Aguirre AN, Fagundes-Neto U. Measurement of low dietary fiber intake as a risk factor for chronic constipation in children. J Pediatr Gastroenterol Nutr. 1999;29(2):132-5. [PubMed: 10435648].

12. Steffen R. Measurement of low dietary fiber intake as a risk factor for chronic constipation in children. Clin Pediatr. 2000;39(4):250-1.

13. Biggs WS, Dery WH. Evaluation and treatment of constipation in infants and children. Am Fam Physician. 2006;73(3):469-77. [PubMed: 16477894].

14. Rubin G, Dale A. Chronic constipation in children. BMJ. 2006;333(7577):1051-5. doi: 10.1136/bmj.39007.760174.47. [PubMed 17110723].

15. Baker SS, Liptak GS, Colletti RB, Croffie JM, Di Lorenzo C, Ector W, et al. Constipation in infants and children: evaluation and treatment. A medical position statement of the North American Society for Pediatric Gastroenterology and Nutrition. J Pediatr Gastroenterol Nutr. 1999;29(5):612-26. [PubMed: 10554136].

16. van Ginkel R, Reitsma JB, Buller HA, van Wijk MP, Taminiau JA, Benninga MA. Childhood constipation: longitudinal follow-up beyond puberty. Gastroenterology. 2003;125(2):357-63. [PubMed: 12891536].

17. Voskuijl WP, Heijmans J, Heijmans HS, Taminiau JA, Benninga MA Use of Rome II criteria in childhood defecation disorders: applicability in clinical and research practice. J Pediatr. 2004;145(2):213-7. doi: 10.1016/j.jpeds.2004.04.050. [PubMed:15289770].

18. Di Lorenzo C, Benninga MA. Pathophysiology of pediatric fecal in continence. Gastroenterology. 2004;126(1 Suppl 1):S33-40. [PubMed 14978636].

19. Loening-Baucke V. Chronic constipation in children. Gastroenterology. 1993;105(5):1557-64. [PubMed: 8224663].

20. Kajbafzadeh AM, Nejat F, Abbaslou P. Comparison of sacral ratio in normal children and children with urinary and/or faecal complaints. Iran J Pediatr. 2008;18(1):57-61.

21. Yousefichaijan P, Cyrus A, Dorreh F, Ahmadi Mohtasham M. Comparing the sacral ratio in children with various degree of Vesicoureteral reflux with children without reflux. AMUJ. 2005;10(3):94-9.

22. Oh JT, Kim HJ, Son SW. Sacral ratio in normal children and patients with anorectal malformations. J Korean Assoc Pediatric Surg. 2000;6(1):32-9.

23. Pe-a A. Anorectal malformations. Seminars in pediatric surgery 1995 Philadelphia, PA: Saunders; 1992.

24. Caicedo O, Moreno L, Montoya R, Jagua A. Comparison of sacral Index in normal paediatric population and patients with constipation, anorectal malformations and vesicoureteral reflux. Rev Colomb Radiol. 2015;26(4):4302-9.

25. Torre M, Martucciello G, Jasonni V. Sacral development in anorectal malformations and in normal population. Pediatr Radiol. 2001;31(12):858-62. doi: 10.1007/s002470100006. [PubMed: 11727021].

26. Macedo M, Martins JL, Freitas Filho LG. Sacral ratio and fecal continence in children with anorectal malformations. BJU Int. 2004;94(6):893-4. doi: 10.1111/j.1464-410X.2004.05053.x. [PubMed: 15476529].

27. Ahmadi J, Kajbafzadeh A, Kalantari M. Evaluation of sacral ratio as a prognostic factor in patients with anorectal malformations. Acta Medica Iranica. 2005;43(2):143-6. 